\title{
Steatocystoma multiplex-natal teeth syndrome
}

INSERM

\section{Source}

INSERM. (1999). Orphanet: an online rare disease and orphan drug data base.

Steatocystoma multiplex-natal teeth syndrome. ORPHA:3184

The syndrome steatocystoma multiplex and natal teeth is characterized by generalized multiple steatocystomas and natal teeth. 